\title{
Sistem Informasi Pelayanan Administrasi Kependudukan Berbasis Website Kelurahan Banaran
}

\section{Web-Based Application of Information System for Population Administration Services in Banaran Village}

Muhammad Vicky Al Hasri ${ }^{1}$, Endah Sudarmilah ${ }^{2}$

Universitas Muhammadiyah Surakarta, Indonesia

\section{Article Info}

\section{Article history:}

Received, 27 Januari 2021

Revised, 20 Mei 2021

Accepted, 23 Mei 2021

\section{Kata Kunci:}

Sistem Informasi

Website

Pelayanan

Administrasi

Kelurahan

\section{Keywords:}

System information

Webiste

Service

Administration

Village

\begin{abstract}
ABSTRAK
Sistem informasi berbasis website berkembang pesat pada saat ini. Salah satu penerapan dalam instansi pemerintah yang dekat dengan masyarakat mengenai pengurusan administrasi ialah lingkup kelurahan. Pelayanan administrasi yang dilakukan secara manual dengan cara datang langsung ke kantor kelurahan sering kali terjadi antrian dan pengelolaan data oleh petugas yang kurang efektif, maka dibangun sistem ini guna melayani berbagai hal administrasi kependudukan di kelurahan. Sistem ini dibuat untuk memberikan kemudahan kepada masyarakat dalam pengajuan pelayanan dan pengelolaan administrasi oleh petugas, penelitian ini memaksimalkan dalam penambahan fitur utama dari hasil penelitian sebelumnya, seperti memberikan pemberitahuan secara langsung yang dikirimkan ke alamat email pemohon dengan melampirkan file surat yang sudah berhasil terverfikasi petugas dan melakukan rekap surat secara otomatis dengan berbentuk laporan dan arsip surat. Pengembangan sistem menggunakan metode waterfall yang meliputi perencanaan, analisis, perancangan, implementasi, dan pemeliharan sistem. Penelitian ini dalam pengujian blackbox sistem menunjukkan seluruh fitur yang ada dapat bejalan dan berfungsi dengan baik dan dalam pengujian melalui System Usability Scale (SUS) diperoleh nilai rata-rata 74.9 yang masuk kedalam kategori baik dan dapat diterima oleh masyarakat.
\end{abstract}

\section{ABSTRACT}

Website-based information systems are growing rapidly at this time. One of the applications in government agencies close to the community is regarding the administrative management of the village scope. Administration services that are carried out manually by coming directly to the village office often have queues and effective data management by officers, so this system was built to serve various population administration matters in the village. This system is made to provide convenience to the public in submitting services and administrative management by officers, this research maximizes the addition of the main features from previous research results, such as providing direct notification sent to the applicant's email address by attaching a letter file that has been verified by the officer and Performing a letter recap automatically with report forms and letter archives. System development uses the waterfall method which includes planning, analysis, design, implementation and maintenance of the system. This research in testing the blackbox system shows that all existing features can function and function properly and in testing through the System Usability Scale (SUS) an average value of 74.9 is obtained which falls into the good category and can be accepted by the community.

This is an open access article under the CC BY-SAlicense.

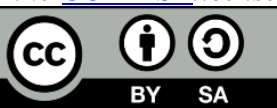

\section{Penulis Korespondensi:}

Muhammad Vicky Al Hasri,

Program Studi Informatika,

Universitas Muhammadiyah Surakarta, Indonesia

Email: L200170065@student.ums. 


\section{PENDAHULUAN}

Revolusi industri 4.0 merupakan era modernisasi dengan ciri, yakni penekanan dalam digital economy, robotic, big data, intelligence, dan digitalisasi lainnya [1]. Era modern ini dimana perubahan dapat dilihat dari kegiatan yang dikerjakan secara manual sebelumnya diubah dengan bentuk digitalisasi, guna dapat memudahkan dan memberikan efisensi waktu dalam pekerjaan. Indonesia merupakan salah satu negara yang menerapkan perubahan tersebut, mulai dari instansi pemerintahan atau swasta terutama dalam pelayanannya. Pelayanan yang diberikan pemerintah kepada setiap warga negara salah satunya ialah pelayanan publik mengenai administratif yang terkait dengan pelayanan pemerintah setempat. Kelurahan merupakan instansi pemerintah terkecil yang secara langsung dekat dengan masyarakat dalam memberikan pelayanan mengenai administrasi kependudukan [2]. Terkait pelayanan publik yang terdapat didalam kelurahan mengenai surat menyurat yang difungsikan sebagi surat keterangan atau surat pengantar.

Kelurahan Banaran merupakan salah satu dari 14 kelurahan yang berada di kecamatan Kalijambe, kabupaten Sragen. Pelayanan publik yang terdapat di kelurahan Banaran khususnya dalam administrasi, yaitu pembuatan surat pernyataan, surat kelahiran, surat kematian, surat belum menikah, surat keterangan tidak mampu, surat berkelakuan baik, surat keterangan usaha, surat domisili, dan lain sebagainya [3]. Maksud dari pengembangan sistem informasi pelayanan administrasi kependudukan di kelurahan Banaran ini karena pelayanan yang tersedia di kelurahan Banaran dalam proses pengajuannya masih sepenuhnya menggunakan cara manual dengan datang langsung ke kantor kelurahan membawa kelengkapan dokumen pendukung, sehingga untuk mendapatkan administrasi yang dibutuhkan dengan cara tersebut kurang efektif dan efisien di era modern saat ini. Selain itu, pendataan surat yang masih dilakukan secara manual dengan menggunakan Microsoft office yang membuat kewalahan petugas dalam melakukan perekapan.

Pemanfaatan teknologi yang tepat sasaran akan memberikan kemudahan dalam melakukan aktivitas dan pekerjaan sehari hari [4]. Saat ini teknologi yang berkembang pesat dan banyak digunakan adalah sistem berbasis website, karena memberikan kemudahan dalam mengakses informasi secara online yang dapat dilakukan dimana saja dengan jaringan internet [5]. Website ialah kumpulan laman berdomain yang menghubungkan antar laman web dengan file-file yang terkait dan menampilkan informasi secara online. Pengunaan teknologi dapat membantu instansi pemerintah untuk meningkatkan mengenai kualitas layanan dan memungkinkan dalam membangun kepercayaan antar elemen, seperti masyarakat, petugas, dan instansi penyedia layanan [6]. Pemanfaatan website dalam instansi pemerintah ialah sebagai sistem informasi yang digunakan menyebarluaskan berbagai informasi yang dibutuhkan oleh semua masyarakat, mengenai hal ini sistem informasi yang tersedia banyak difungsikan berbagai macam, contohnya sistem informasi administrasi. Sistem informasi administrasi berguna sebagai pelayanan masyarakat mengenai surat menyurat dan dibangun guna membantu untuk mengatasi mengenai sistem yang tersedia dalam bentuk manual [7]. Adanya sistem informasi berbasis website akan memberikan kemudahan dalam komunikasi dua arah serta dapat mendukung penyampaian informasi mengenai pengiriman berkas elektronik yang dapat dilakukan tanpa dibatasi oleh ruang dan waktu [8].

Penerapan teknologi informasi berbasis website akan memberikan kemudahan dan dampak yang baik terhadap pelayanan publik [9]. Penelitian sebelumnya terdapat sistem informasi pelayanan administrasi kependudukan yang dibangun, namun belum sepenuhnya dapat memudahkan petugas kantor kelurahan dalam melakukan perekapan mengenai surat dan pembuatan laporannya secara otomatis dalam sistem, sehingga petugas harus melakukan dua kali kerja untuk merekap surat yang ada [10] dan [11]. Kemudian mengenai rancang bangun sistem informasi pelayanan desa yang dapat memudahkan dalam pembuatan permohonan surat dan menginformasikan mengenai data pajak setiap warga, namun kekurangannya dari sistem tersebut setiap masyarakat melakukan pengajuan tidak adanya pemberitahuan mengenai pengajuan apakah disetujui atau tidak [12].

Perbedaan yang mendasar dengan penelitian sebelumnya, sistem yang dihasilkan sekarang terdapat pengembangan fitur baru dalam sistem dan hak akses dalam melakukan pengajuan surat keterangan dari kelurahan Banaran. Mulai penambahan mengenai akses pengajuan surat dapat secara langsung dilakukan oleh masyarakat yang membutuhkan dengan mengunjungi website dan melakukan registrasi dan pengisian form pengajuan yang tersedia, selain itu terdapat penambahan fitur tentang pelaporan data surat guna menghindari penumpukan dokumen dan memberikan pemberitahuan berupa notifikasi surat yang dapat langsung masuk ke email atau ke akun pengguna. Sistem ini dalam pengembangannya menggunakan bahasa pemrograman PHP dengan framework Laravel sehingga akan menjamin keamanan sistem dan menggunakan Mysql yang difungsikan sebagai database serta Bootstrap sebagai framework untuk front end agar memberikan user interface yang baik dan responsive. Sehingga dalam pengembangan sistem berbasis website ini dapat digunakan oleh kelurahan Banaran dengan baik dan memberi kemudahan kepada petugas dan masyarakat mengenai proses administrasi.

\section{METODE PENELITIAN}

Metode yang digunakan dalam penelitian ini adalah Research and Development (R\&D) yang bertujuan untuk mengembangkan dan menghasilkan sistem yang dapat memberikan solusi atas kendala pelayanan administrasi yang dilakukan secara manual.

Setiap langkah metode penelitian ini digambarkan seperti proses pengembangan sistem informasi pelayanan administrasi kependudukan dengan model SDLC (system development life cycle) pendekatan Waterfall dengan UML (unified modelling language) yang terdapat use case diagram dan activity diagram. Keterkaitan antara ketiga metode tersebut ialah bertujuan melakukan pengembangan sistem yang sudah ada sebelumnya dengan menambahkan fitur baru, serta dalam konsep pengembangan rekayasa perangkat lunak terutama dalam penelitian ini yaitu pengembangan sistem berbasis website setiap 
prosesnya terstruktur dan berurutan. Metode Waterfall (air terjun) ialah model sekuensial linier yang menekankan pengembangan secara sistematis yang terdiri dari tahapan analisis kebutuhan, design sistem, implementasi, pengujian, dan pemeliharaan [13] dan [14]. Detail alur tahapan-tahapan penelitian dalam perancangan dan pengembangan sistem ini terdapat pada diagram alir Gambar 1 .

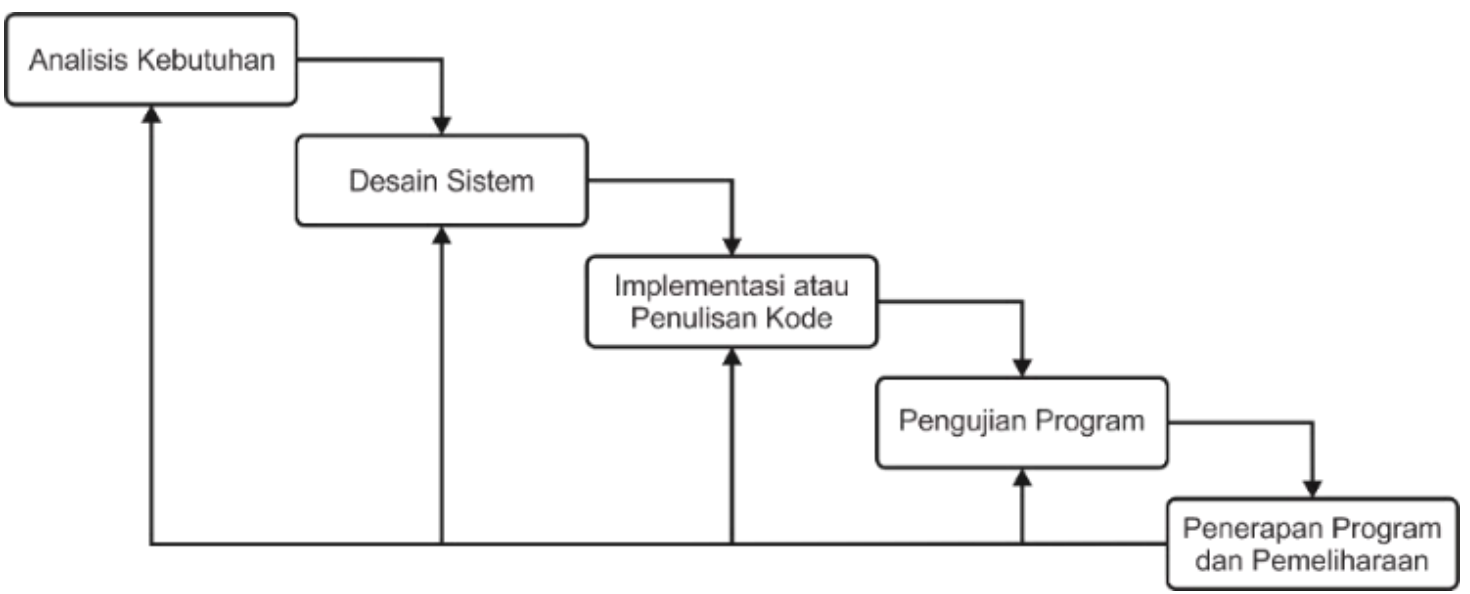

Gambar 1. Tahapan Metode System Development Life Cycle (SDLC) Waterfall [15]

Berikut merupakan penjelasan tahapan dari metode SDLC Waterfall:

\subsection{Analisis Kebutuhan}

Melakukan pengumpulan data yang dilakukan dengan wawancara bersama pihak yang bersangkutan. Tujuan utama dalam tahap ini ialah mengumpulkan informasi guna dapat memenuhi kebutuhan dan fungsi terhadap sistem yang akan dibangun. Pelayanan administrasi di kelurahan Banaran menunjukkan kurang efektif dalam proses pelayanan administrasinya, sehingga perlunya pengembangan sistem untuk mengatasi kondisi tersebut dengan membangun Sistem Informasi Pelayanan Administrasi Kependudukan Berbasis Website.

Kebutuhan fungsional dari sistem ini yakni mengenai generate surat keterangan atau surat pengantar yang berisi nomor surat, jenis surat, data diri pengaju, keterangan, tanggal pembuatan, dan keterangan lainnya. Semua data yang berada disurat akan terekap kedalam database dan akan menjadi laporan mengenai surat keluar. Alur mendapatkan surat tersebut dengan cara warga melakukan registrasi dan login kedalam sistem, kemudian melakukan pengajuan surat dengan mengisi form. Sistem ini terdapat administrator guna melakukan pengelolaan setting pada sistem secara langsung dan melakukan pemantauan mengenai pelayanan berupa verifikasi pengajuan surat dari masyarakat.

Kebutuhan non fungsional meliputi kebutuhan dari perangkat keras yang digunakan untuk proses develop sistem dan entry data kedalam sistem, sedangkan perangkat lunak yang digunakan meliputi Sistem Operasi Windows 10, Composer, Xampp, Visual Studio Code dan Mozilla Firefox.

\subsection{Desain Sistem}

Tahap ini menggunakan UML (unified modelling language) yang terdapat use case diagram dan activity diagram. UML merupakan bahasa yang digunakan sebagai spesifikasi standar untuk mendokumentasikan dan membanngun perangkat lunak [16].

\subsection{Use Case Diagram}

Use case diagram digunakan untuk memberikan gambaran interaksi antara aktor dengan sistem [17]. Use case pada Gambar 2, menjelaskan mengenai setiap level user berserta tindakan yang dapat dilakukan terhadap sistem. Admin, dalam level user admin dapat melakukan login kedalam sistem, melakukan tindakan mengelola dan mengolah informasi dalam sistem dan mengelola setiap level user. Petugas, dalam level user petugas dapat melakukan tindakan login kedalam sistem dan dapat mengelola berbagai pengajuan dalam pelayanan yang masuk dalam sistem, mengakses rekap surat, mengakses data warga, dan mengelola level user masyarakat. Masyarakat, dapat mengakses sistem secara langsung dan dapat melakukan pengajuan dalam pelayanan dengan registrasi terlebih dahulu kedalam sistem. 


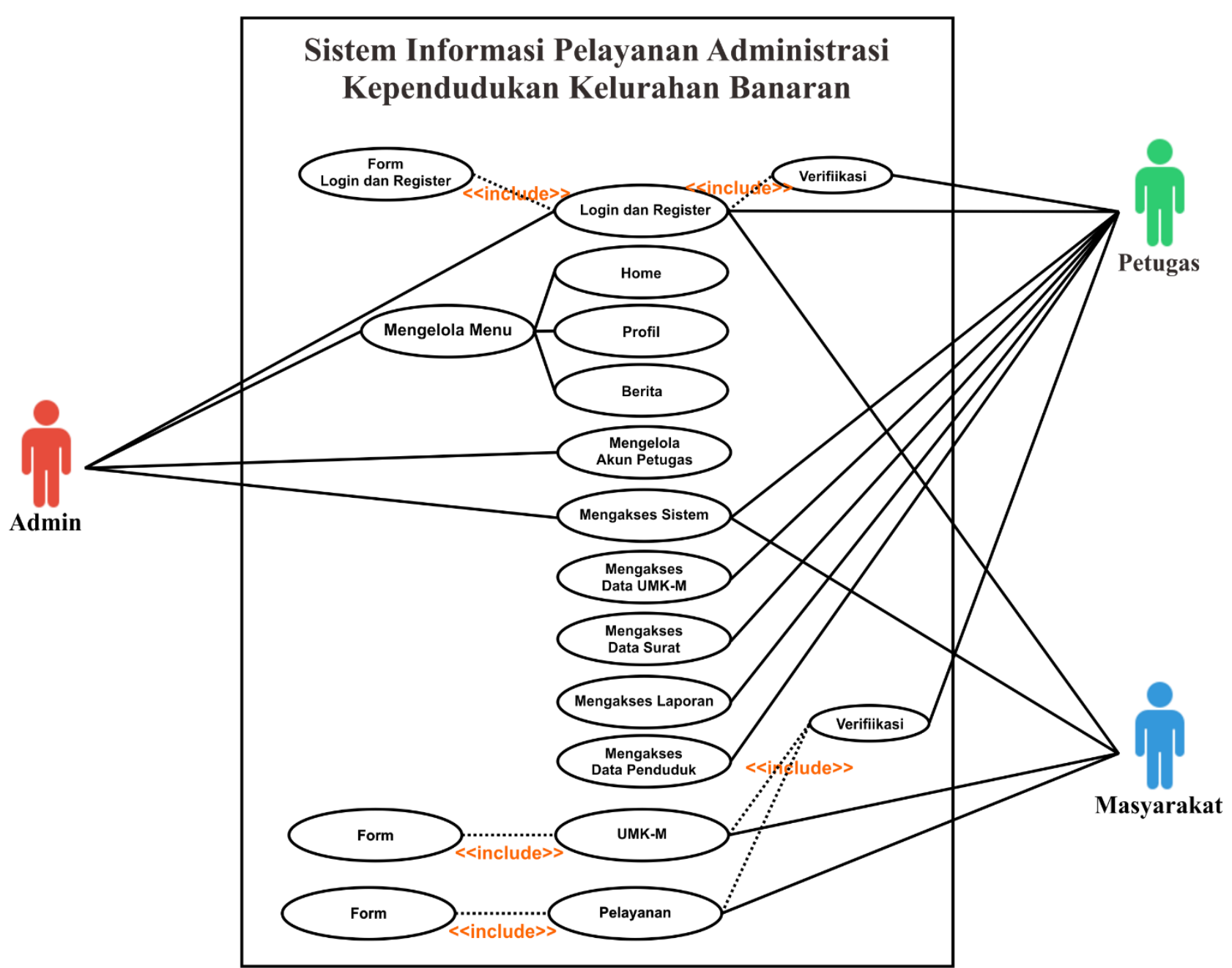

Gambar 2. Use Case Diagram

\subsection{Activity Diagram}

Activity diagram menggambarkan kumpulan proses workflow dalam sistem [18]. Gambar 3 menjelaskan bahwa Sistem Informasi Pelayanan Administrasi Kependudukan Kelurahan Banaran terdapat 3 level user, yakni warga atau masyarakat yang berada di desa Banaran, petugas berupa perangkat dari kelurahan, dan admin. Setiap level user memiliki hak akses dalam pengelolaan sistem. Level masyarakat dapat melakukan pengajuan pelayanan berupa surat pengantar atau surat keterangan melalui sistem namun harus teregistrasi sebelumnya dan mendapatkan verifikasi dari petugas. Level user petugas dapat mengelola data masuk mengenai pengajuan dalam pelayanan dari masyarakat mengelola registrasi masuk dari level user masyarakat, mengakses rekap surat, dan mengakses data warga. Level user admin ialah mengolah informasi dalam setiap menu sistem serta dapat mengelola semua level user. 


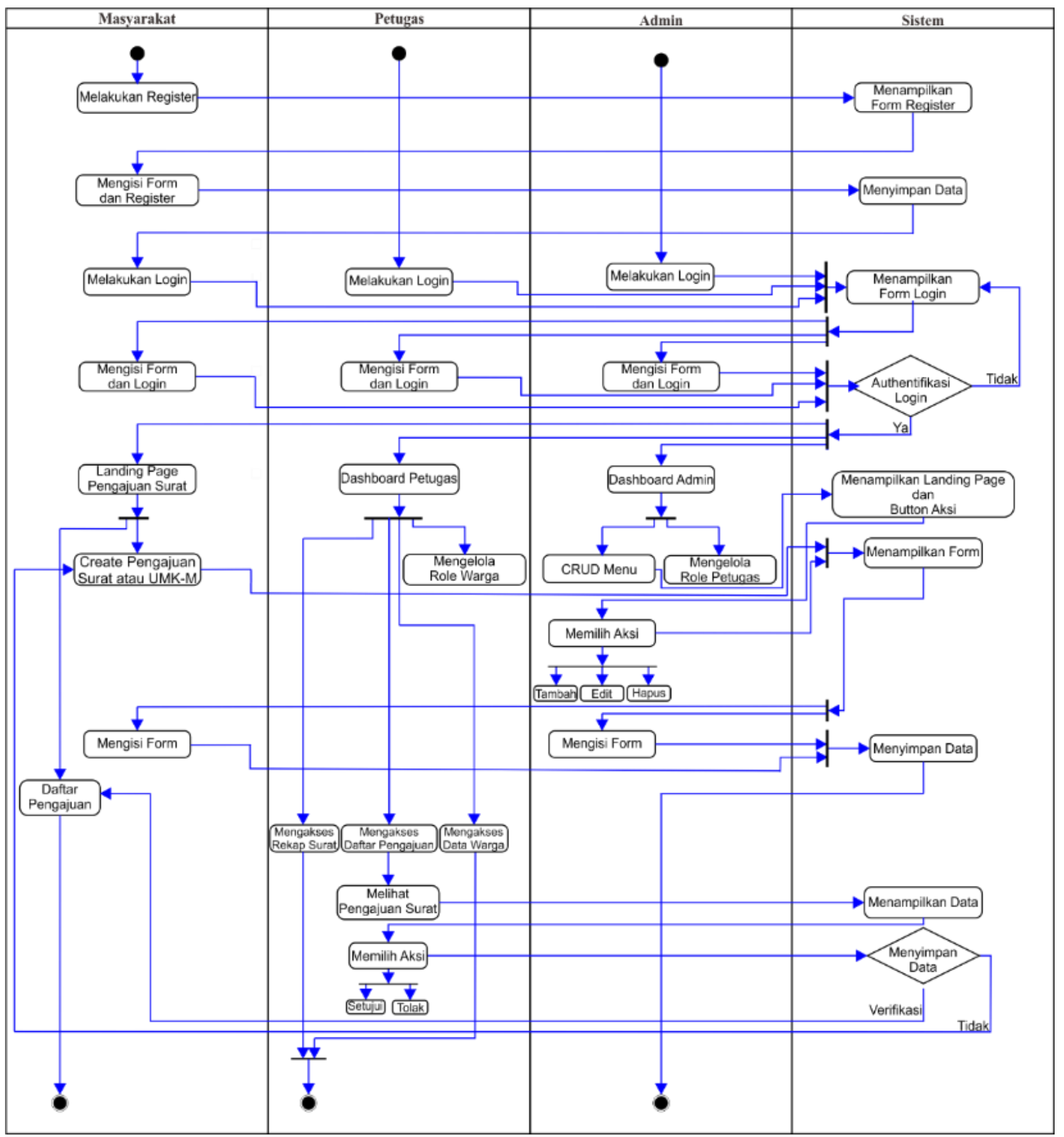

Gambar 3. Activity Diagram

\subsection{Entity Relation Diagram}

Entity Realtional Diagram (ERD) merupakan representasi grafis dari desain database yang akan dibangun secara konseptual [19]. ERD menunjukkan hubungan atribut dalam entitas dan hubungan antar entitas [20], mengenai hubungan antar entitas guna mempermudah dalam pengunaan atribut data yang sama antar entitas. Pada gambar 4 terdapat banyak entitas guna dapat mengelompokan atribut data agar membentuk entitas sederhana, fleksibel, dan menghindari redudansi. Sehingga dalam perancangan ini memberikan gambaran mengenai database yang akan diterapkan dalam sistem dengan baik. 


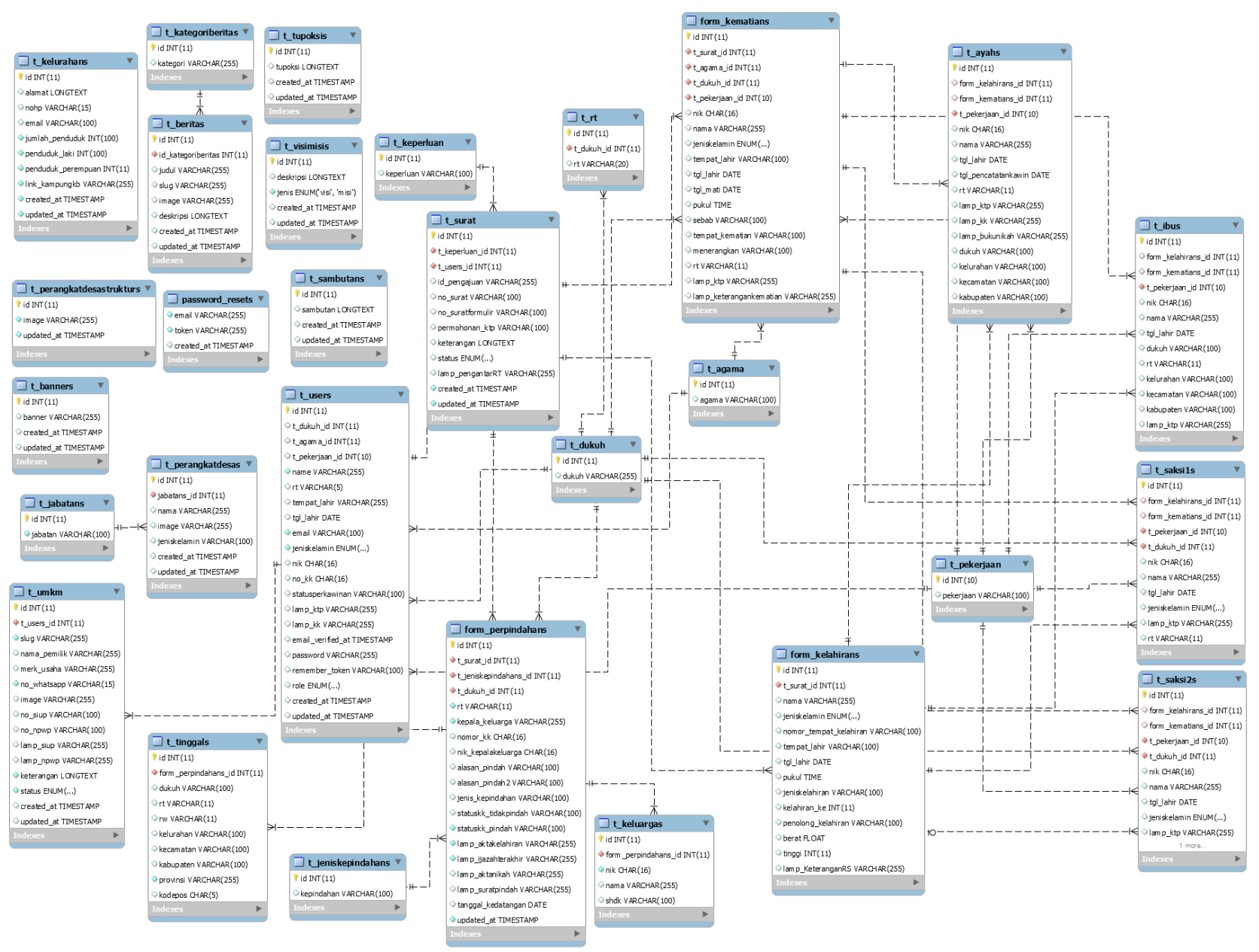

\subsection{Wireframe}

Gambar 4. Entity Relation Diagram (ERD)

Wireframe merupakan rancangan user interface sistem yang akan dibangun dalam bentuk mock up design. Gambar 5 menampilkan bentuk wireframe dari landing page dan Gambar 6 menampilkan bentuk wireframe dari dashboard page sistem informasi pelayanan administrasi kependudukan kelurahan banaran.

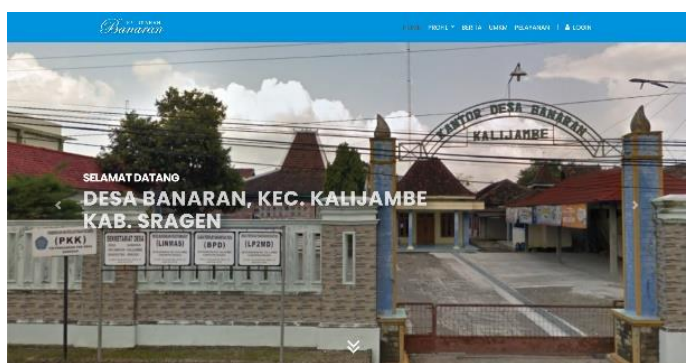

Gambar 5. Wireframe Landing Page

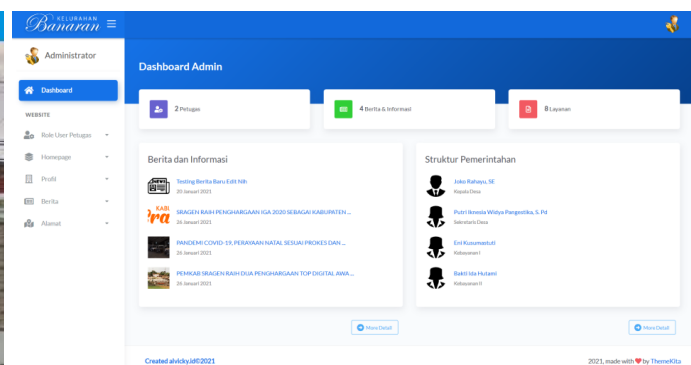

Gambar 6. Wireframe Dashboard Page

\subsection{Implementasi atau Penulisan Kode}

Bentuk implementasi dari semua desain yang telah dirancang melalui tahap coding agar dapat berjalan dalam bentuk sistem berbasis website. Proses pada tahap ini dilakukan dengan menggunakan perangkat lunak atau tools, yakni windows 10 sebagai sistem operasi, visual studio code sebagai text editor yang berfungsi untuk penulisan kode program, xampp sebagai server local yang berfungsi untuk mengelola database, composer sebagai tools dependency manager pada bahasa pemrograman PHP (hypertext preprocessor) yang berfungsi sebagai penghubung dengan library dari luar, dan mozilla firefox untuk menjalankan sistem. Bagian dalam sistem dibangun dengan menggunakan framework Laravel sebagai back end dan framework Boostrap sebagai front end. 


\subsection{Pengujian Program}

Langkah pengujian terhadap sistem setelah dibuat. Pengujian dengan menggunakan metode black box testing dan usability testing menggunakan System Usability Scale (SUS) yang diperkenalkan oleh John Broke. Black box testing merupakan pengujian yang dilakukan berdasarkan informasi dari spesifikasi, fokus pada pengujian ini hanya pada keluaran yang dihasilkan sebagai bentuk respon terhadap masukan yang diberikan kesistem [21]. System Usability Scale (SUS) ialah kuisioner yang digunakan sebagai pengukuran atau penilaian sistem secara subyektif dari sudut pandang pengguna [22]. Penujian SUS pada penelitian ini berjumlah 30 responden dengan melibatkan beberapa tokoh masyarakat dari kelurahan Banaran. Hasil dari pengujian ini akan dijadikan sebagai tolak ukur untuk dilakukan perbaikan atau pengembangan sistem agar lebih baik.

\subsection{Penerapan Program dan Pemeliharaan}

Implementasi secara langsung sistem yang selesai dibangun untuk dapat digunakan dan pemeliharaan terhadap sistem yang dikelola oleh petugas. Tahap ini dilakukan untuk memastikan apabila sistem mengalami masalah atau proses dalam kinerjanya.

\section{HASIL DAN ANALISIS}

Penelitian ini menghasilkan sistem informasi yang dapat mempermudah dalam melakukan pengajuan mengenai pelayanan yang berada di Kelurahan Banaran, serta dapat membantu petugas dalam melakukan perekapan surat keluar. Sistem ini selain digunakan sebagai pengajuan pelayanan secara online, terdapat fitur tambahan mengenai pendaftaran umkm atau usaha yang dimiliki oleh penduduk kelurahan Banaran guna membantu branding dan promosi terhadap khalayak umum. Adanya sistem informasi pelayanan administrasi kependudukan ini bertujuan agar dapat memberikan kemudahan akes masyarakat dalam melakukan pengajuan mengenai administratif yang berkaitan dengan kelurahan secara langsung dan online, selain itu dapat memberikan banyak kemudahan terutama petugas pelayanan dalam mengelola administrasi khususnya dalam pelayanan masyarakat. Penelitian ini menghasilkan sistem informasi berbasis website yang memiliki fitur pemberitahuan secara langsung yang dikirimkan ke alamat email pemohon dengan melampirkan file surat yang sudah berhasil terverfikasi petugas dan melakukan rekap surat secara otomatis dengan berbentuk laporan dan arsip surat guna memudahkan pengguna dalam berinteraksi secara langsung dengan sistem.

\subsection{Halaman Utama}

Halaman utama yakni laman yang pertama kali tampil saat mengakses sistem. Gambar 7 menunjukkan menu yang terdapat berbagai macam menu yang terdapat dalam sistem, menu login difungsikan untuk melakukan akses login kesistem sesuai dengan level user pengguna.

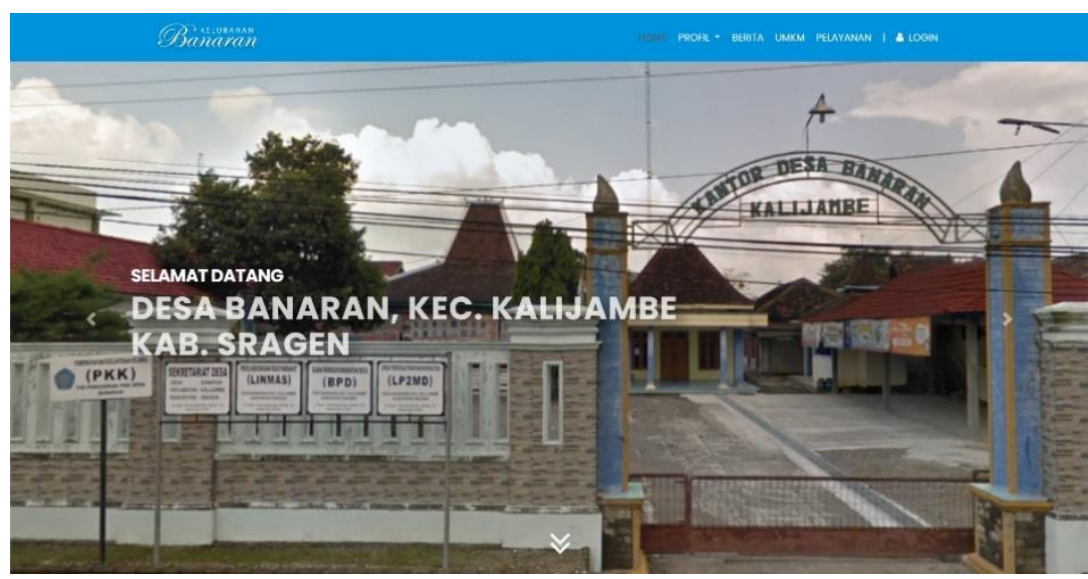

Gambar 7. Halaman Utama

\subsection{Form Pelayanan}

Form Pelayanan yakni sebagai tempat untuk menerima masukan dari pengguna yang selanjutnya akan disimpan kedalam database. Sebagai contoh pada Gambar 8 ialah form pelayanan pengajuan akta kelahiran dan Gambar 9 ialah form yang digunakan untuk melakukan upload dokumen sebagai persyaratan pengajuan pelayanan. 


\section{Bamaran}

Akta Kelahiran

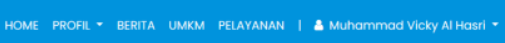

Home > Pelayanan > Akta Kelahiran

FORM AKTA KELAHIRAN

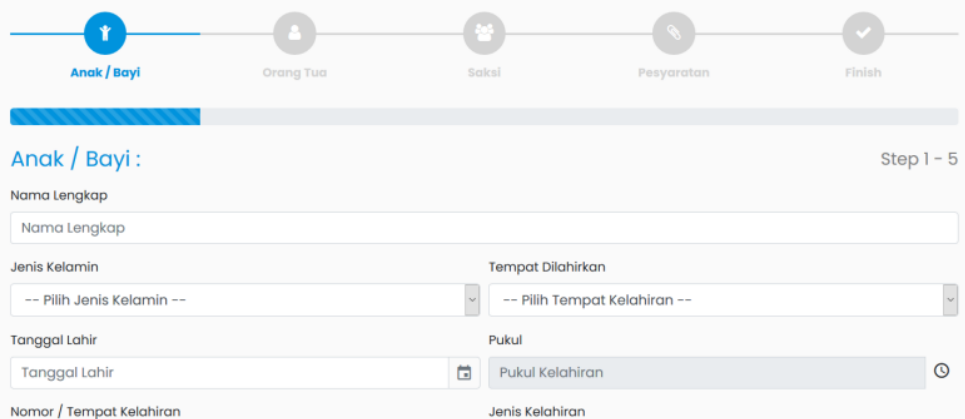

Gambar 8. Form Pelayanan

Gambar 8 ialah form pelayanan pengajuan akta kelahiran, halaman tersebut menampilkan berbagai form yang berisi pertanyaan - pertanyaan yang berkaitan dengan data yang dibutuhkan dalam membuatan akta kelahiran.

FORM AKTA KELAHIRAN

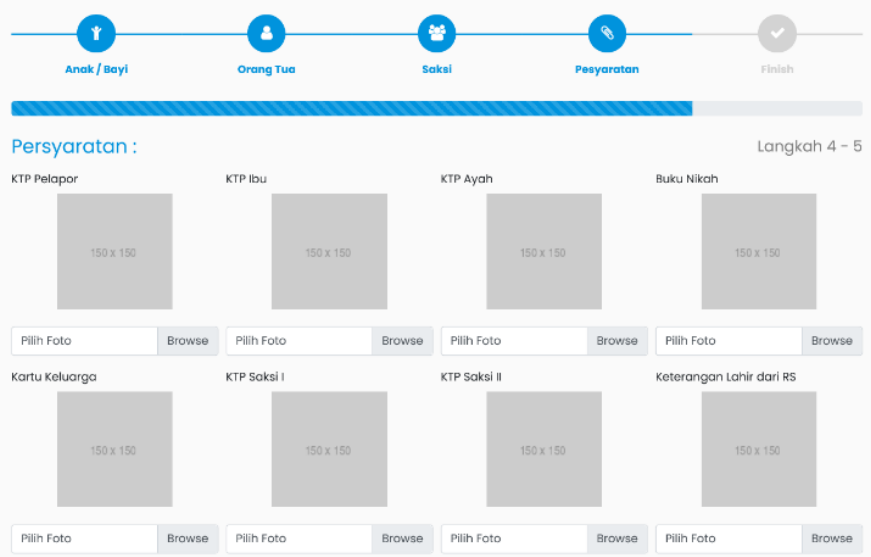

Gambar 9. Form Upload Persyaratan

Gambar 9 merupakan user interface dari form yang digunakan untuk melakukan unggah dokumen sebagai persyaratan pengajuan pelayanan, dokumen yang dapat diunggah berupa file ekstensi png atau jpeg agar lebih mudah dijangkau masyarakat dalam praktik pengoperasian sistem dalam mengunggah dokumen.

\subsection{Halaman Login}

Halaman Login yakni halaman yang difungsikan untuk melakukan authentifikasi sistem. Seperti Gambar 10 agar dapat masuk ke dashboard atau dapat melakukan pengajuan pelayanan user diharuskan untuk memasukkan alamat email dan password yang disudah didaftarkan sebelumnya. 


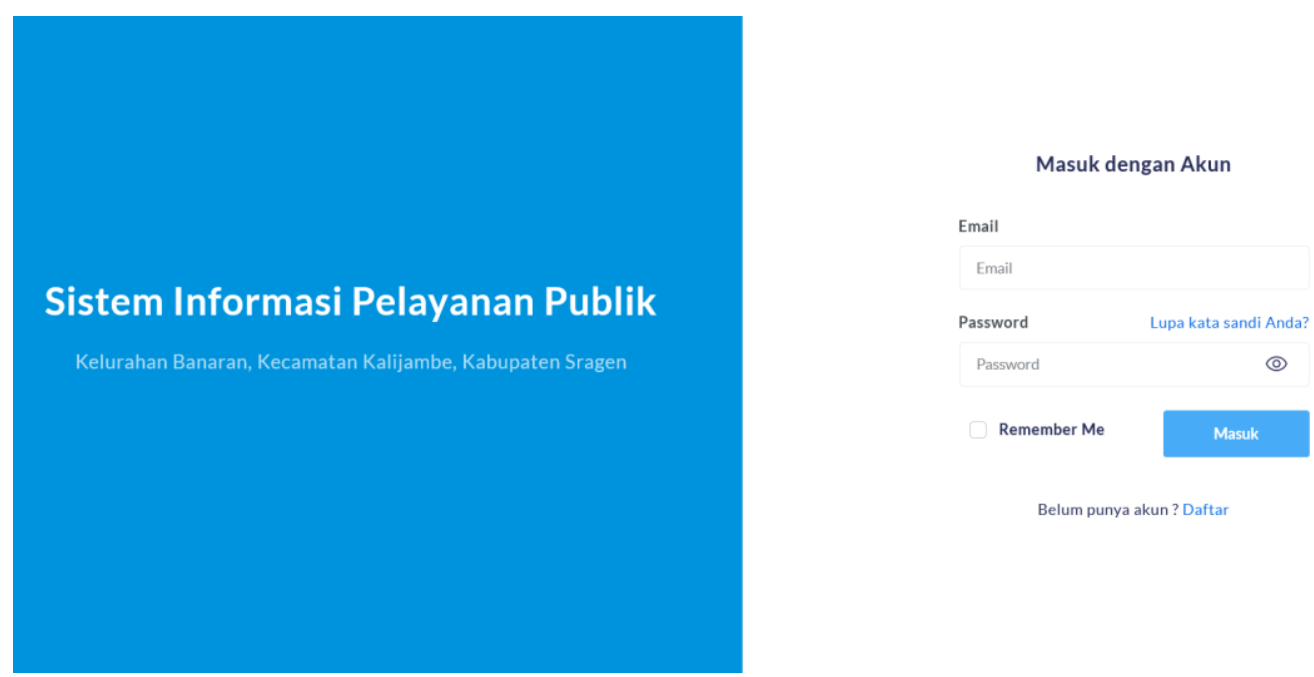

Gambar 10. Halaman Login

\subsection{Dashboard Admin}

Dashboard admin yakni laman yang digunakan sebagai landing page dengan level pengguna admin saat melakukan login sebelumnya. Sesuai dengan Gambar 11 menunjukkan bahwa dashboard ini digunakan sebagai kustomisasi website serta dalam melakukan publish berita atau informasi.

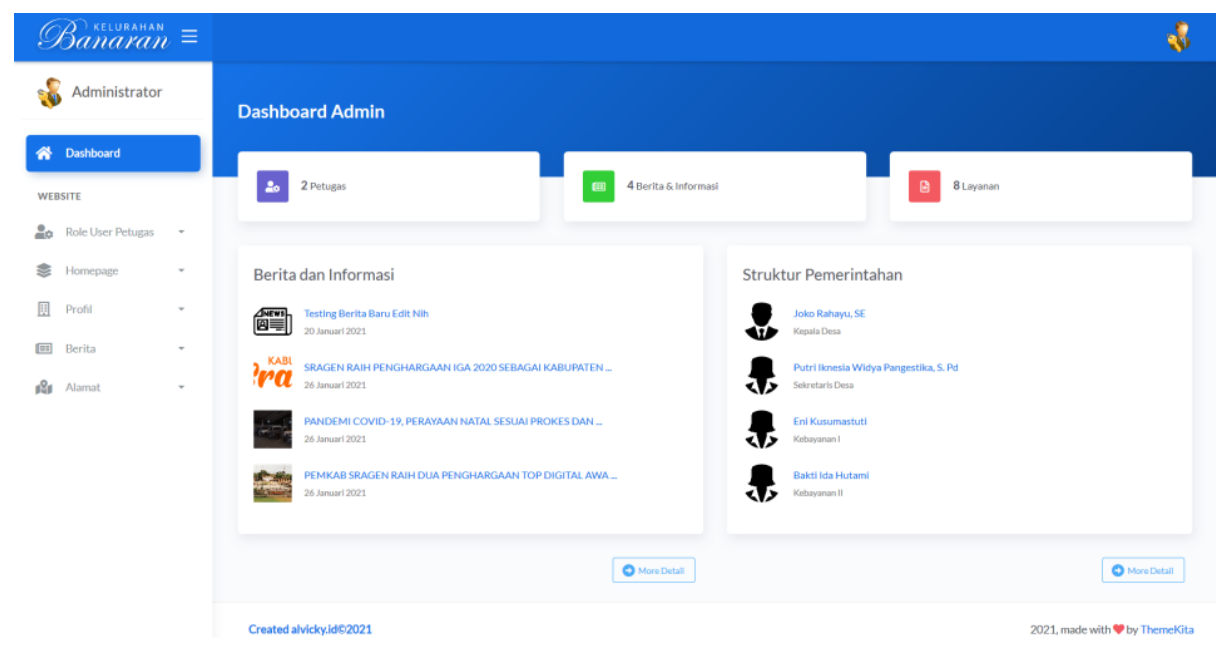

Gambar 11. Dashboard Admin

\subsection{Dashboard Petugas}

Dashboard petugas yakni laman yang digunakan sebagai landing level pengguna user petugas saat melakukan login sebelumnya. Sesuai dengan Gambar 12 menunjukkan bahwa dashboard ini digunakan sebagai verifikasi mengenai berbagai pengajuan dari masyarakat dan berfungsi untuk mencetak laporan.

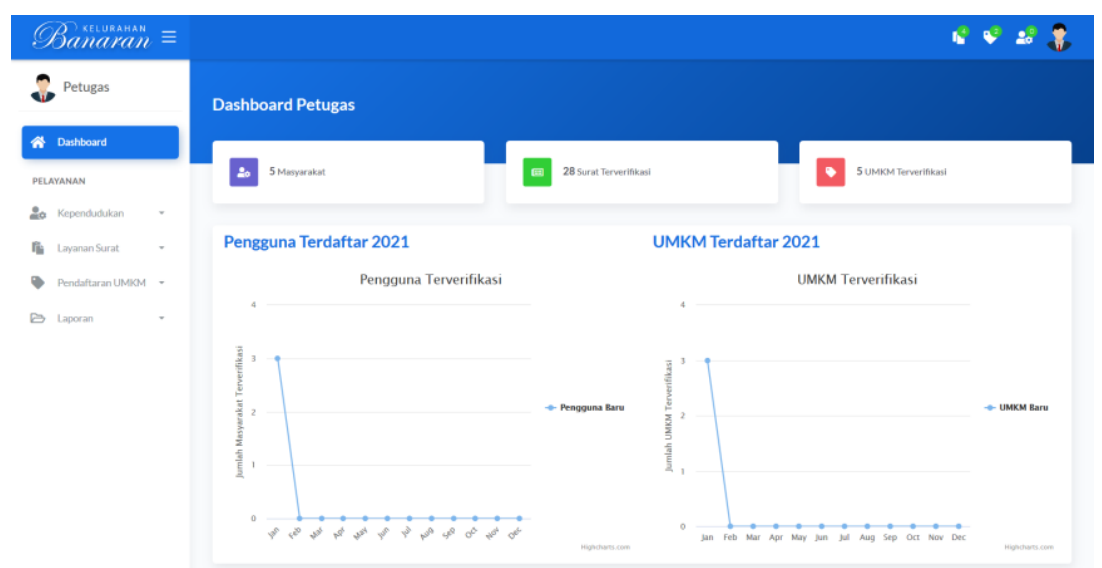

Gambar 12. Dashboard Petugas 


\subsection{Dashboard Masyarakat}

Dashboard masyarakat yakni laman yang digunakan sebagai landing level pengguna user masyarakat saat melakukan login sebelumnya. Sesuai dengan Gambar 13 menunjukkan bahwa dashboard ini digunakan untuk melihat riwayat pengajuan.

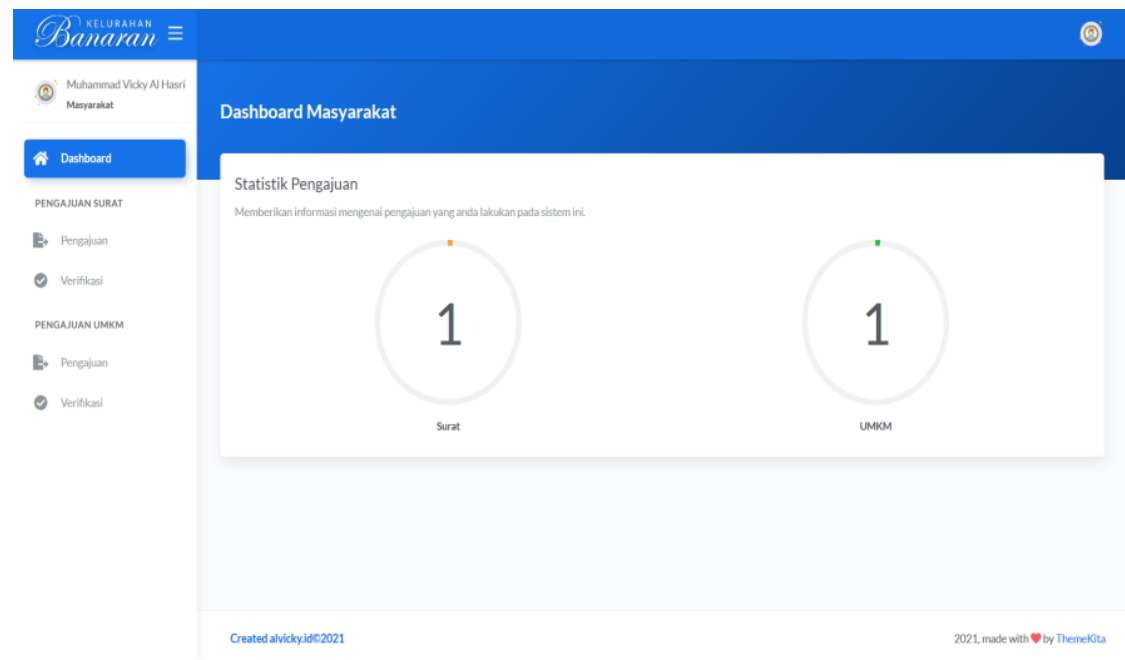

Gambar 13. Dashboard Masyarakat

\subsection{Laporan}

Laporan yakni hasil dari seluruh pengajuan yang telah diverifikasi oleh petugas, yang kemudian dapat di ekspor dalam bentuk file pdf. Cara ekspor pdf dilihat pada Gambar 14 terdapat dua pilihan, yaitu dengan filter berdasarkan rentang tanggal dan ekspor seluruh data.

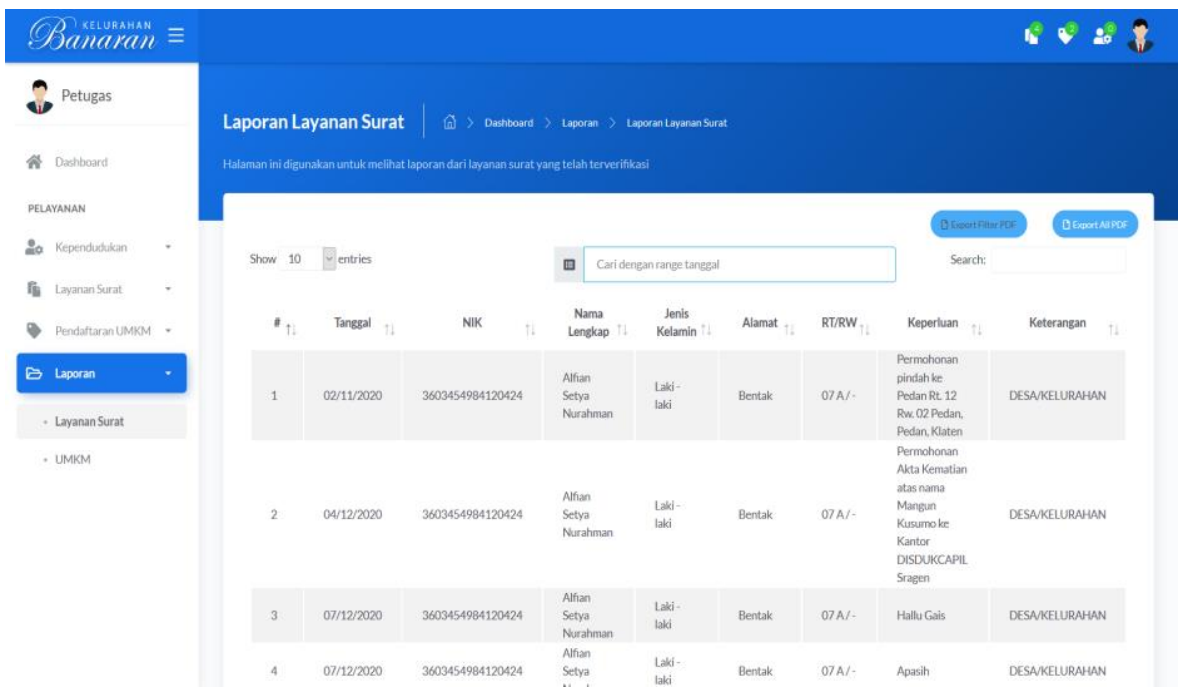

Gambar 14. Laporan

\subsection{Hasil Pengajuan Terverifikasi}

Pengajuan yang berhasil terverifikasi akan mendapatkan feedback berupa balasan yang dikirimkan ke alamat email saat registrasi. Sesuai dengan Gambar 15 balasan email akan terlampir file berupa surat keterangan dan surat lampiran dalam bentuk file pdf. 


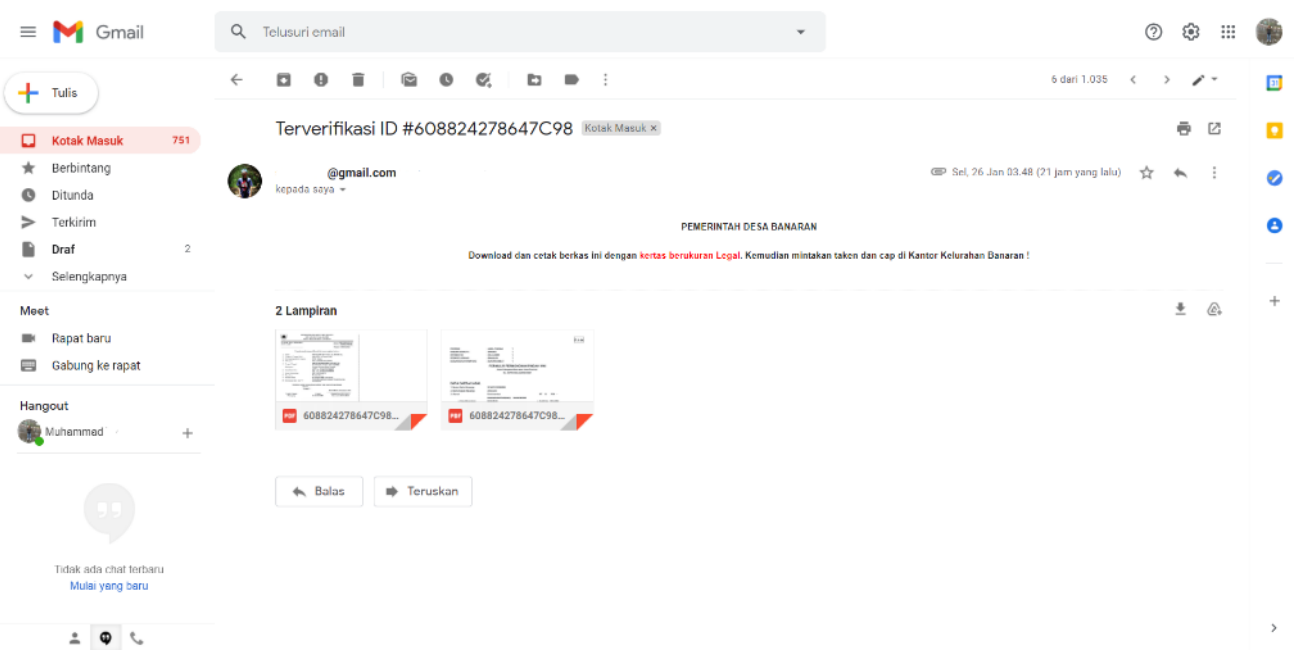

Gambar 15. Hasil Pengajuan Terverifikasi

\subsection{Pengujian Blackbox}

Pengujian blackbox dilakukan bertujuan untuk memastikan seluruh fitur pada sistem dapat berfungsi dengan baik. Bagian ini dilakukan pengujian fungsionalitas setiap fitur yang dimiliki role user dengan memberikan masukan terhadap sistem secara langsung berupa klik button, masukan pada form, dan sebagainya. Hasil yang didapatkan pada pengujian ini menunjukkan sistem dengan seluruh fitur dan alur pemprosesan yang ada dapat bejalan dan berfungsi dengan baik.

\subsection{Pengujian System Usability Scale}

System Usability Scale terdiri dari 10 pertanyaan dengan skala linkert yaitu Sangat Tidak Setuju (STS) dengan skor 1 sampai dengan Sangat Setuju (SS) dengan skor 5. Perhitungan dengan menggunakan SUS terdapat peraturan tersendiri yakni setiap pertanyaan bernomor ganjil, skor setiap pernyataan yang didapat dari responden akan dikurangi 1, kemudian pertanyaan bernomor genap, skor akhir didapat dari nilai 5 dikurangi skor pertanyaan yang didapat dari responden, terakhir nilai SUS didapat dari hasil penjumlahan skor tiap pertanyaan kemudian dikali 2,5.

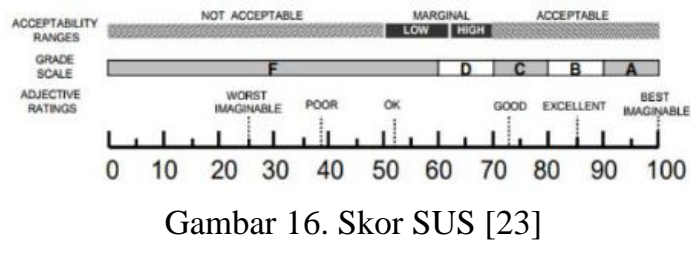

Berdasarkan hasil pengujian menggunakan System Usability Scale (SUS) dengan 30 reponden yang terlibat, mendapatkan nilai 74.9. Seperti ditunjukkan dalam Gambar 15 skor yang didapatkan masuk kedalam kategori baik dan dapat diterima oleh masyarakat.

\section{KESIMPULAN}

Sistem Informasi Pelayanan administrasi kependudukan berdasarkan hasil pengujian dengan menggunakan blackbox secara keseluruhan fitur bekerja sesuai dan berjalan dengan baik, hal itu dibuktikan selama dilakukan pengujian tidak terdapat error yang ditemukan. Sistem dapat membantu dalam pelayanan administrasi dengan cara mengirimkan kembali berupa file surat ke alamat email secara langsung kepada pelapor. Berdasarkan pengujian SUS didapatkan nilai rata-rata 74.9 yang dapat disimpulkan sistem yang dibangun termasuk kedalam kategori baik yang dapat memberikan kemudahan atas kendala dalam pelayanan administrasi secara konvensional atau datang langsung ke kantor kelurahan. Namun secara keselurahan sistem informasi pelayanan administrasi kependudukan masih belum sempurna sehingga dapat dikembangkan lagi agar pengguna memiliki experience lebih baik. Perbaikan sistem dapat dilakukan dengan menerapkan ajax pada setiap pemrosesannya, sehingga sistem lebih interaktif dan user friendly ketika digunakan. Selain itu, dapat mengembangkan sistem dengan android webview agar memberikan kenyamanan terhadap pengguna dalam mengoperasikan dengan perangkat mobile secara langsung. 


\section{REFERENSI}

[1] R. S. Muharam, “Inovasi Pelayanan Publik Dalam Menghadapi Era Revolusi Industri 4.0 Di Kota Bandung," Decision: Jurnal Administrasi Publik, vol. 1, no. 01, pp. 39-47, 2019.

[2] B. Muhammad and A. Bahar, "Model Aplikasi Sistem Pelayanan Terpadu Pada Kantor Kelurahan," Teknik Informatika, vol. 5, no. 1, pp. 877-1021, 2016.

[3] Munawir, Zulfan, Y. Yanti, and Erdiwansyah, "Perancangan Sistem Manajemen Administrasi Gampong Berbasis Aplikasi Desktop," Jurnal Serambi Engineering, vol. 2, no. 4, pp. 182-187, 2017.

[4] F. Simangunsong and A. Djaga, "Program Implementation of E-Government-Based Village Administration and Information System in West Sumba Regency,” Asian Journal of Management Sciences \& Education, vol. 7, no. 10, pp. 71-82, 2018.

[5] M. I. Mustofa and Z. Mustofa, "Web-based village information system," International Research Journal of Engineering and Technology (IRJET), pp. 595-600, 2018.

[6] N. Riawati, "Village Innovation Through Village Information Administration System (Said) in Bondowoso District East Java Province," The International Seminar Series on Regional Dynamics, vol. 1, no. 1, pp. 277-288, 2019.

[7] A. D. Rahmawati and A. Fatmawati, "Sistem Administrasi Desa Mendiro Kecamatan Ngrambe Kabupaten Ngawi Berbasis Web," Emitor: Jurnal Teknik Elektro, vol. 18, no. 01, pp. 1-7, 2020.

[8] Soegiarto, E. C. Kirana, and Bahar, "Model aplikasi sistem pelayanan administrasi penduduk berbasis web pada kantor kelurahan," Jurnal Teknologi Informasi dan Komunikasi, vol. 9, no. 2, pp. 9-18, 2018.

[9] I. M. Wahyu Hidayat Ibrahim, "Sistem Informasi Pelayanan Publikberbasis Web Pada Dinas Pekerjaan Umum Kabupaten Kampar," Jurnal Ilmiah Rekayasa dan Manajemen Sistem Informasi, vol. 3, no. 2, pp. 17-22, 2017.

[10] M. Huda, S. Wiyono, M. F. Hidayatullah, and S. Bahri, "Studi Kasus: Sistem Informasi dan Pelayanan Administrasi Kependudukan," Komputika : Jurnal Sistem Komputer, vol. 9, no. 1, pp. 59-65, 2020.

[11] A. Ahmadi and H. Juliansa, "Rancang Bangun Sistem Informasi Digital Layanan Administrasi Publik Desa Berbasis WEB Responsive," Jurnal Ilmiah Informatika Global, vol. 10, no. 1, 2019.

[12] E. M. Rini, F. Panduardi, and F. Romansah, "Rancang Bangun Sistem Informasi Pelayanan Desa Tamansari Kecamatan Licin Banyuwangi Berbasis Web," Seminar Nasional Teknologi Informasi dan Multimedia 2016 STMIK AMIKOM Yogyakarta, pp. 145-150, 2016.

[13] C. Tristianto, "Waterfalls," Gooseberry, vol. 12, no. 01, pp. 41-56, 2018.

[14] D. Handayani and A. Noeman, "Sistem Informasi E-Administrasi ( KTP , KK , Surat Pengantar Nikah , Surat Kelahiran dan Surat Kematian ) Berbasis Web," vol. 4, no. 1, pp. 65-74, 2019.

[15] R. Ritnawati, R. Suppa, and M. Muhallim, "Sistem Informasi Pelayanan Masyarakat Berbasis Android Pada Kantor Desa Kaliba Mamase," SPEKTA (Jurnal Pengabdian Kepada Masyarakat : Teknologi dan Aplikasi), vol. 1, no. 2, pp. 95-100, 2020.

[16] A. Hendini, "Pemodelan Uml Sistem Informasi Monitoring Penjualan Dan Stok Barang (Studi Kasus: Distro Zhezha Pontianak)," Crop Science, vol. 4, no. 2, pp. 201-205, 2016.

[17] A. Gunanto and E. Sudarmilah, "Pengembangan Website E-Arsip di Kantor Kelurahan Pabelan,” Emitor: Jurnal Teknik Elektro, vol. 20, no. 02, pp. 104-110, 2020.

[18] Suendri, "Implementasi Diagram UML (Unified Modelling Language) Pada Perancangan Sistem Informasi Remunerasi Dosen Dengan Database Oracle (Studi Kasus: UIN Sumatera Utara Medan)," Jurnal Ilmu Komputer dan Informatika, vol. 3, no. 1, pp. 1-9, 2018.

[19] A. Syukron, "Perancangan Sistem Informasi Administrasi Kependudukan Desa Berbasis Website Pada Desa Winong," Bianglala Informatika, vol. 7, no. 1, pp. 16-21, 2019.

[20] K. Hidayat, "Modeling Information System for Agroindustry of Jamu Madura," Teknika: Engineering and Sains Journal, vol. 2, no. 1, pp. 47-52, 2018.

[21] M. Larrea, "Black-Box Testing Technique for Information Visualization. Sequencing Constraints with Low-Level Interactions," Journal of Computer Science and Technology, vol. 17, no. 1, pp. 37-48, 2017.

[22] B. Said and F. Prasetyo E.P., "Layanan e-Surat Berbasis Mobile Application di Desa Waru Barat Pamekasan," InfoTekJar (Jurnal Nasional Informatika dan Teknologi Jaringan), vol. 4, no. 1, pp. 111-115, 2019.

[23] Rasmila, "Evaluasi Website Dengan Menggunakan System Usability Scale (SUS) Pada Perguruan Tinggi Swasta Di Palembang," JUSIFO : Jurnal Sistem Informasi, vol. 2, no. 1, pp. 108-121, 2018. 